\title{
ROLE OF DISSPRO AND CBSP ON CURRENT SEED SUPPLY SITUATION IN NEPAL
}

Suroj Pokhrel PhD ${ }^{1}$

\section{ABSTRACT}

The seed replacement rate of major field crops is very low, about $8 \%$, in Nepal with $92 \%$ seed supply of major field crops from informal sector. Different seed production initiatives are undertaken by public and private sectors. However, their role and effectiveness on seed sector development have not been assessed. A review on secondary data related to seed production and usage and primary data collected from different public and private organizations in the year 2011were used to assess the role of District Level Seed Self Sufficiency Program and Community Based Seed Production program on current seed supply situation in Nepal. DISSPRO is the most popular, widely adopted and cheapest seed producing program with annual production of $40.4 \%$ followed by CBSP $3.83 \%$ of the total certified/improved seeds in the country. The seed production trend of DISSPRO and CBSP is rapidly increasing. Strengthening seed sector through the integration of DISSPRO, CBSP and other seed initiatives together with effective enforcement of seed regulation for quality seed multiplication, distribution and use is necessary for rapid rise on SRR, enhancing crop production and food security in Nepal.

Key words: CBSP, crop production, DISSPRO, food security, seed sector, SRR

\section{INTRODUCTION}

An estimated 60 percent of households cannot meet their own food needs, especially in mountainous areas, and agricultural production only meets food requirements for three to eight months per year in Nepal (Action against Hunger, 2006). The food security situation of the country is becoming more challenging due to climate change, political and economical instability. Seed, fertilizer and irrigation are the major inputs to improve production and productivity. Quality seeds of improved and desired varieties are the most important and least expensive agricultural input but its availability and accessibility at right time and location is playing important role to determine the local productivity, production and food security. Presently, there are four different agencies: public sector led (NARC, DOA, NSC etc), community led (DISSPRO, CBSP, CSB, Cooperatives), private led (SEAN, Agro vets, Seed Companies) and import led (SEAN, Agro vets, importers and distributors) are involving in seed sector development in Nepal (CDD, 2011a: CDD, 2011b). However, the seed replacement rate (SRR) of major field crops at present in Nepal is very low (about 8\%), seed supply is mostly from informal sectors (SQCC, 2011). District Level Seed Self Sufficiency Program (DISSPRO), Community Based Seed Production (CBSP) program, Commercial Seed Production Program and Community Seed Bank are seed initiatives taken by CDD/DoA. District Level Seed Self Sufficiency Program (DISSPRO) and Community Based Seed Production program (CBSP) are the major initiatives started during 9th five-year plan by the government to have local level seed sufficiency of the major cereals in the country (CDD, 2011a). They are claimed to be taking major role on local level improved seed availability over other GO, NGOs or private led agencies at present, and it is needed to be verified. Nepal Agriculture Research Council is responsible for crop breeding, varietal improvement, source seed production and supply. Strengthening seed sector for rapid rise on SRR is necessary for to enhance crop production and food security in Nepal.

\footnotetext{
${ }^{1}$ Crop Development Directorate, DoA, Nepal, surojpokhrel@yahoo.com
} 


\section{OBJECTIVES}

The specific objectives are:

To assess the present seed production situation of major field crops in Nepal

To assess the role of DISSPRO and CBSP on current seed supply situation in Nepal

\section{METHODOLOGY}

An intensive review was carried out for assessing the status of seed production initiatives in Nepal in the year 2011. The progress report of Nepal Agriculture Research Council (NARC), Crop Development Directorate, Seed Quality Control Centre, information in web pages and the literature available were reviewed to gather the secondary information. The data on source seed production by the farms and stations of Nepal Agriculture Research Council (NARC)during the last three years (2008/09-2010/011) were collected from Seed Technology and Development Division, Khumaltar. Primary data on certified/improved seeds produced during last three years (2008/09-2010/011) from government seed production programs (District Seed Sufficiency Programs, Commercial Seed production Programs, Community Seed Banks, Governments farms, Government supported National Seed Company and Corporation) and private sectors (commercial farmers groups, cooperatives and registered private companies) were collected from the concerned authorities and Crop Development Directorate. The data collected were mainly of major cereals, pulses, oilseeds and other minor field crops. The data on seed replacement ratewere collected from Seed Quality Control Section. All the data were tabulated and analyzed to access the role of DISSPRO, CBSP and other seed initiatives in Nepal.

\section{REVIEW ON SEED SYSTEM IN NEPAL}

\section{EXISTING SEED POLICY AND LEGISLATION}

Agriculture Enterprise Promotion Policy-2063, Agriculture Biodiversity Policy-2063, National Agricultural Policy 2061, National Seed Policy-2056, Seed Act- 2045 and Seed Regulation, 2054 and Community Seed Bank Guideline are the major policies and legislation related to seed sector development and regulation in Nepal. However, there are some gaps in existing policy and legislation where, the supply system is dominated by informal seed system, well equipped laboratories and qualified manpower are not sufficient, harmonization of acts and regulations with international agreements, effective enforcement of law and implementation of seed program is necessary.

\section{SOURCE SEED PRODUCTION}

Breeder seed production of major cereal crops of Nepal i.e., rice, maize and wheat was $37.12 \mathrm{mt}$ in the year 2010/011. NARC produced $855.8 \mathrm{mt}$ foundation (rice 404 , maize 103.6, wheat 328.1 , millet 1.0 , moong 0.9 , lentil 10.1 , mustard 4.8 , jute 1.8 and cowpea $1.5 \mathrm{mt})$ seeds in the same year. This quantity is sufficient if seed cycle would be maintained (Seed Technology Division, 2011; SQCC, 2011).



Fig.1: Cereal seed supply situation in Nepal

\section{SEED CYCLE AND LOCAL SEED EXCHANGE}

Nepal Agriculture Research Council (NARC) claimed to be sufficient in breeder and foundation seed to maintain seed cycle, however it is not true in practice resulting insufficient quantity supply of certified/ improved seed. Only $8 \%$ of the seed is supplied 
from the formal sector whereas, $92 \%$ is supplied through farm saved seeds and local exchange (Fig.1).

\section{PROBLEMS AND CHALLENGES}

There is a strong need of developing a long term national seed strategy, vision and plan. Strong linkage of research, extension, education and private sectors on seed production needed. There is only limited varietal option for remote areas (as maize in Karnali). Even in the accessible areas, the extension education on seed production especially the Participatory Variety Selection (PVS), IRD, demonstration, training, etc. are insufficient. Seed skills of the front line extension workers are poor. Seed quality control mechanism is very weak. Sometimes quality of seed is poor (without possessing, tagging, bagging, and underweight, etc). Production and distribution system of C1 and C2 seed is very weak to maintain the seed cycle. Miss use of seeds, poor technical knowhow, and low seed holding capacity of the poor rural farmers with limited storage and processing facilities are prevailed. Private sector involvement is very limited. Investment in seed sector is very poor. Seed marketing network is fragile. The seed production initiatives eg DISSPRO is under funding. All these constraints are making inconsistent and insufficient seed supply enabling to maintain the seed cycle (CDD, 2010). To improve the efficiency of seed marketing, broader use of truthful labeling (TL), branding and developing small infrastructure are essential. The new threats such as uncertainty of climate and diseases: GLS, Physoderma, etc on seed production are arising. Capacities of the majority seed producing farmers are very poor to address all these challenges and also they are not sufficiently aware on quality seed (CDD, 2011a).

\section{FINDINGS OF THE STUDY}

\section{CERTIFIED/IMPROVED SEED PRODUCTION}

Different seed production initiatives have been taken in Nepal. At present, all these efforts have been succeeded to produce and distribute only $17542.67 \mathrm{mt}(2009 / 010)$ certified/improved seeds of major field crops. DISSPRO is producing a highest amount of certified/ improved seeds (12554mt) followed by government supported National Seed Co.

Table 1. Certified/improved seed production (CDD, 2011a)

\begin{tabular}{lrrr}
\hline Organization & \multicolumn{3}{c}{ Certified/improved seed production $(\mathrm{mt})$} \\
\cline { 2 - 4 } & $2008 / 2009$ & $2009 / 2010$ & $2010 / 2011$ \\
\hline DISSPRO/Groups/Coop. & 4077.000 & 7040.810 & 12554 \\
CBSP-HMRP (Maize) & 427.000 & 673.000 & 1146 \\
CSB Bank & 00.00 & 135.000 & 142 \\
Sundarpur-Chandradangi farms & 00.00 & 133.116 & 115.452 \\
NICDP (Jute, Mustard) & 1.500 & 2.740 & 3.4 \\
National seed co. & 3936.157 & 4522.422 & $\mathrm{NA}$ \\
Private companies & 4875.662 & 4183.746 & $\mathrm{NA}$ \\
Salt Trading & 580.900 & 607.610 & 610.0 \\
NGO and others & 166.280 & 244.228 & $\mathrm{NA}$ \\
Total & 14064.5 & 17542.67 & 14570.85 \\
\hline
\end{tabular}

(4522.422mt), and different private companies/cooperatives (4183.746mt $\mathrm{N}=17)$. Among other seed production initiatives the Community Based Seed Production Program (CBSP/HMRP) supported from CIMMYT is being able to produced $1146 \mathrm{mt}$, Salt Training 
Corporation (government supported) 610mt, Government supported Community Seed Bank (CSB) 142mt, Government farms (Sundarpur and Chandradangi) 115.452mt and National Industrial Crop Development Program (NICDP) 3.4mt annually at present (Table 1).

\section{ROLE OF DISSPRO AND CBSP ON CERTIFIED/IMPROVED SEED PRODUCTION}

DISSPRO is producing about $40.4 \%$ of total certified seeds in the country. Where, GO supported National Seed Company (NSC) is producing $25.8 \%$, Private Registered Companies 23.85\% ( $\mathrm{N}=17)$, and CBSP $6.84 \%$ of the total certified/improved seeds (Table 1, Fig. 2$)$. The seed production trend of DISSPRO (12554mt in 2010/2011) and CBSP (1146mt) is rapidly increasing compare to rest of other seed initiatives in the country (Fig.3).

Table 2. Certified/improved seed production in 2009/010 (CDD, 2011a)

\begin{tabular}{|c|c|c|c|c|c|c|c|c|c|c|c|}
\hline \multirow[t]{2}{*}{ SN } & \multirow[t]{2}{*}{ Crop } & \multicolumn{10}{|c|}{ Seed produced from different programs $(\mathrm{mt})$} \\
\hline & & DISSPRO* & CBSP & CSB & Go & NICDP & NSC & STC & Pvt.Co. & NGOs & Total \\
\hline 1 & Rice & 3761.50 & 00.00 & 49.00 & 111. & 00.00 & 958. & 00.00 & 1641.60 & 127.01 & 6649.37 \\
\hline 2 & Maize & 8.13 & 673.00 & 42.00 & 1.43 & 00.00 & 0.05 & 00.00 & 307.58 & 15.10 & 1827.28 \\
\hline 3 & Wheat & 2419.03 & 00.00 & 44.00 & 20.3 & 00.00 & 3554 & 607.61 & 2036.11 & 91.84 & 8773.48 \\
\hline 4 & Moong & 3.60 & 00.00 & 00.00 & 00.0 & 00.00 & 00.0 & 00.00 & 1.25 & 4.67 & 9.52 \\
\hline 5 & Lentil & 41.50 & 00.00 & 00.00 & 00.0 & 00.00 & 6.25 & 00.00 & 150.48 & 5.61 & 203.84 \\
\hline 6 & Rapesee & 20.36 & 00.00 & 00.00 & 00.0 & 1.20 & 1.54 & 00.00 & 21.50 & 00.00 & 44.60 \\
\hline 7 & Rajma & 2.20 & 00.00 & 00.00 & 00.0 & 00.00 & 00.0 & 00.00 & 9.05 & 00.00 & 11.25 \\
\hline 8 & Cowpea & 3.44 & 00.00 & 00.00 & 00.0 & 00.00 & 00.0 & 00.00 & 11.37 & 00.00 & 14.81 \\
\hline 9 & Barley & 1.05 & 00.00 & 00.00 & 00.0 & 00.00 & 00.0 & 00.00 & 00.00 & 00.00 & 1.05 \\
\hline 10 & Jute & 00.00 & 00.00 & 00.00 & 00.0 & 1.54 & 1.12 & 00.00 & 2.92 & 00.00 & 5.58 \\
\hline \multirow[t]{2}{*}{11} & Millet & 00.00 & 00.00 & 00.00 & 00.0 & 00.00 & 00.0 & 00.00 & 1.90 & 00.00 & 1.90 \\
\hline & Total & 7040.8 & 673.0 & 135.0 & 133. & 2.7 & 4522. & 607.6 & 4183.8 & 244.2 & 17542.7 \\
\hline
\end{tabular}

*12554.09mt in 2010/011

Note: DISSPRO=District Seed Sufficiency Program, CBSP=Community Based Seed Production Program, CSB=Community Seed Bank, Go= Government Farms, NICDP = National Industrial Crop Development Program, NSC= National Seed Company, STC = Salt Trading Corporation, Pvt.Co.= Private Seed Companies, NGOs= Non-Government Organization



Fig.2: Improved/ certified seed production\%, (CDD, 2011a)

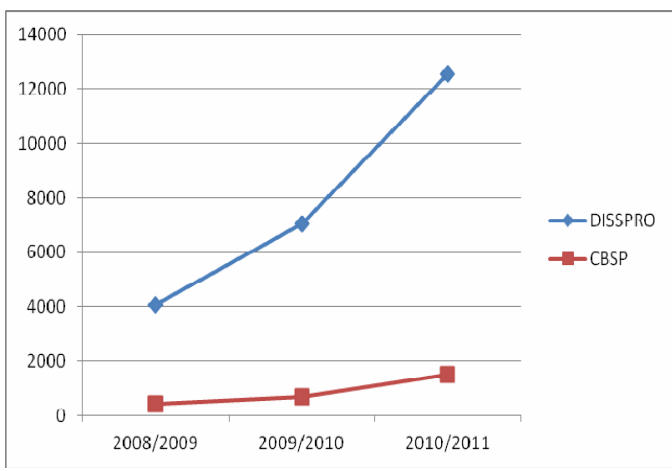

Fig.3: Progression of DISSPRO and CBSP (mt/year) 


\section{CROP WISE CERTIFIED/IMPROVED SEED PRODUCTION}

Among the total certified seeds produced in Nepal highest volume was wheat $(50.01 \%)$ followed by rice $37.9 \%$, maize $10.42 \%$ and lentil $1.16 \%$. Negligible seeds were produced in rest of other crops (Table 2 ). Where, the highest volume under DISSPRO was rice $(53.4 \%)$ followed by wheat (34.36\%) and maize (11.19\%) in the year 2009/2010. Other minor seed producing crops under DISSPRO were Moong, Lentil, Rapeseed, Rajma, Cowpea and Barley (Fig.4 and 5). CBSP supported from HMRP/CYMMIT is involved on maize seed production in 20 mid-hill districts. CSB and GO farms are mainly involved on rice, maize and wheat seed production. Where, NICDP is involving on rapeseed and jute seed production, STC on wheat seed and NSC and private Co. on wheat, rice and lentil seed production in Nepal.

\section{SUPPORT PROVIDED ON SEED INITIATIVES IN NEPAL}

Major supports provided from CDD/DoA for seed production initiatives are: source seed management, technical backstopping, information support, revolving fund support, training and small infrastructure support e.g. threshing floor, storage and processing equipments, seed bins etc.

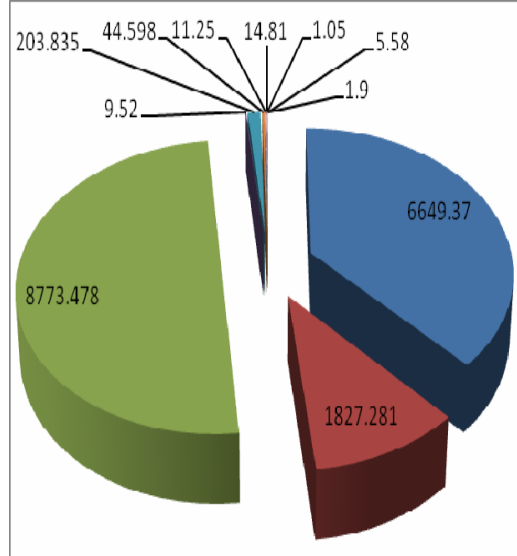

Fig.4: Improved seed produced in 2009/010

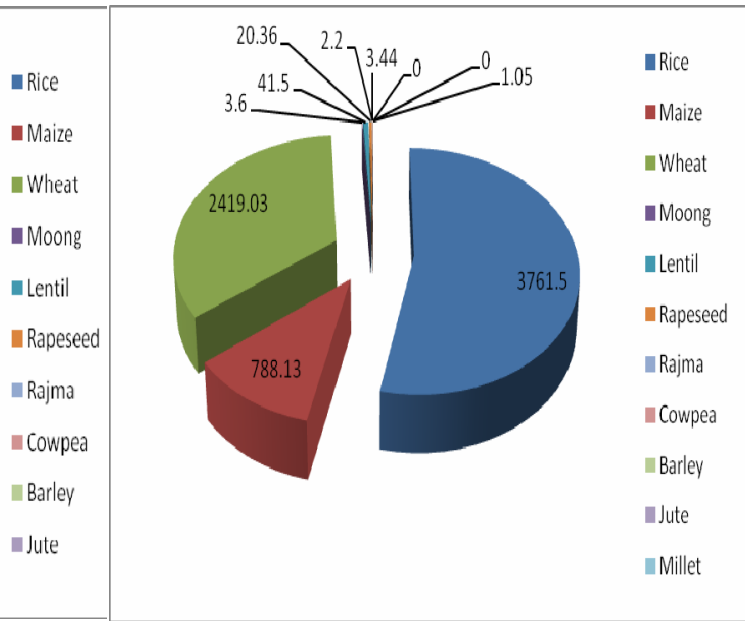

Fig.5: Seeds produced under DISSPRO in 2009/010

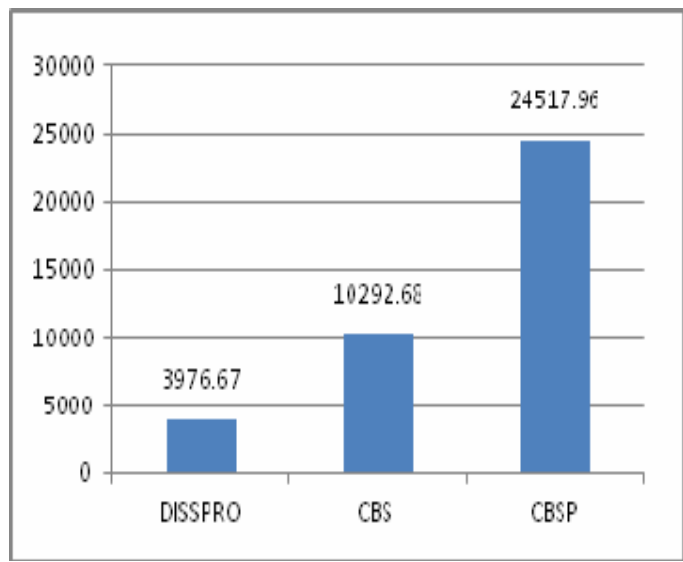

Fig.6: Cost of CDD seed production initiatives (NRs/mt), (CDD, 2011a)

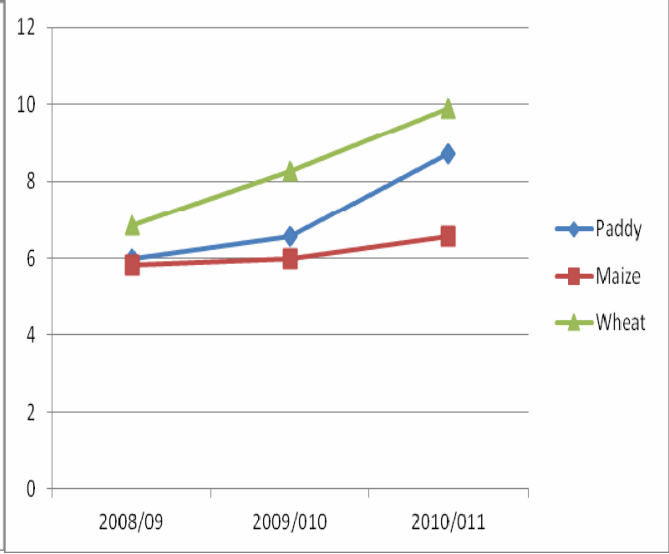

Fig.7: \% SRR of major cereals over the years 


\section{COST OF SEED INITIATIVES IN NEPAL}

DISSPRO is the most popular, widely adopted (300 with 77 commercializing farmers groups/cooperatives) and cheapest seed program initiatives in the country. The minimum support was provided from the government of Nepal for producing one metric ton of improved/certified seeds under DISSPRO (NRs 3976.67) and that was larger in CBS (NRs 10292.68) and highest in CBSP (NRs 24517.96) (Fig.6). Where, the costs of producing seeds in case of rest of other initiatives are to be further accessed.

\section{SEED REPLACEMENT RATE}

Total seed requirement of the major crops in Nepal is estimated 212407.8mt annually, total seed supply and seed replacement rate in different years seems very low. The SRR is 8.7, 6.55 and 9.88 for the major cereals rice, maize and wheat; however, it is increasing throughout the years (Table 3, Fig.7). DISSPRO is playing leading role on the total SRR in the country (Table 1).

Table 3. SRR Trend of Nepal (SQCC, 2010)

\begin{tabular}{|c|c|c|c|c|c|c|c|c|c|}
\hline \multirow{2}{*}{$\begin{array}{l}\text { FY } \\
\text { Crop }\end{array}$} & \multicolumn{3}{|c|}{$2008 / 2009$} & \multicolumn{3}{|c|}{$2009 / 2010$} & \multicolumn{3}{|c|}{$2010 / 2011$} \\
\hline & $\begin{array}{l}\text { TSR } \\
\text { (mt) }\end{array}$ & $\begin{array}{l}\text { TSS } \\
\text { (mt) }\end{array}$ & $\begin{array}{c}\text { SRR } \\
\%\end{array}$ & $\begin{array}{l}\text { TSR } \\
(\mathrm{mt})\end{array}$ & $\begin{array}{l}\text { TSS } \\
\text { (mt) }\end{array}$ & $\begin{array}{c}\text { SRR } \\
\%\end{array}$ & $\mathrm{TSR}(\mathrm{mt})$ & TSS (mt) & $\begin{array}{c}\text { SRR } \\
\%\end{array}$ \\
\hline Paddy & 77472 & 4643 & 5.99 & 77463 & 5071 & 6.55 & 77797 & 6768 & 8.7 \\
\hline Maize & 17019 & 990 & 5.81 & 17403 & 1040 & 5.98 & 17508 & 1147 & 6.55 \\
\hline Wheat & 80645 & 5531 & 6.85 & 84777 & 7007 & 8.27 & 83394 & 8245 & 9.88 \\
\hline Millet & NA & NA & NA & 2655 & 3 & 0.11 & 2659 & 53.18 & 2 \\
\hline Lentil & NA & NA & NA & 5685 & 32.96 & 0.58 & 7352 & 230.5 & 3.13 \\
\hline Rapeseed & NA & NA & NA & 1533 & 17.36 & 1.13 & 1841 & 51.85 & 2.85 \\
\hline Vegetables & NA & NA & NA & 1457 & 1036.7 & 71 & $1457^{*}$ & $1036.7^{*}$ & 71 * \\
\hline Others & NA & NA & NA & NA & NA & NA & $20399.8^{*}$ & $1019.99^{*}$ & $5.0^{*}$ \\
\hline Total & 175234 & 11164 & 6.3 & 190973 & 14208 & 7.44 & 212407.8 & 18579.4 & 8.75 \\
\hline
\end{tabular}

*Estimated

Note: TSR= Total Seed Required, TSS= Total Seed Supplied, SRR= Seed Replacement Rate

\section{CONCLUSIONS}

- Based on the review and the analysis of the data following conclusions are drawn:

- The seed system in Nepal is not strong enough. There are some gaps in existing seed policy, plan and programs. Weak enforcement of seed law (acts, regulations and standards) together with need of harmonization of with international agreements is the challenges.

- The seed production and supply system is inconsistent and insufficient enabling to maintain the seed cycle in a chain. It is due to poor capacities (Technical and physical) of the seed producing farmers, front line extension workers and seed entrepreneurs involved in different seed initiatives.

- There are more than half dozen seed production initiatives taken by the government of Nepal including the involvement of private sector. They are working with different capacities and financial supports. Private sector involvement in these initiatives is very 
limited. Investment in these seed production initiatives is very poor. The seed marketing network is fragile.

- DISSPRO and CBSP are the key seed strategies of the Government of Nepal (GoN) to increase food production and food security in the country. DISSPRO is a cost effective, popular and most successful seed production initiative. Increased the size of the program and sufficient funding could sufficiently contribute on higher seed replacement rate.

\section{RECOMMENDATIONS}

- Based on the finding of the study following recommentations are made:The technical and physical capacities of the seed producing farmers, extension workers and the seed entrepreneurs should be strengthen. It involves technical training in Farmers Field School mode and establishing infra structure and equipment supports.

- Conduct basic research: developing location specific technologies, variety development and maintenance, scaling up variety selection and dissemination activities through PVS, IRD and demonstrations is needed.

- Improving the awareness on quality seed among general farmers, promote entrepreneurial skill among seed producers, coordination among different actors and need of single funnel seed output system in Nepal are equally important.

- Developing coping mechanism against the new threats such as uncertainty of climate, insect pests and diseases is recommended

- The involvement of private sector should be enhanced with increased investment in seed sector and improving the seed marketing network on Public Private Partnership basis. Broader use of truthful labeling (TL) and seed branding is recommended for enhancing the seed marketing. Introduction of the partial pre payment system will provide opportunities to resource poor farmers to sale their seeds.

- Government should increase the funding on seed sector development for increase food production and food security in the country. Special support should be provided to DISSPRO because of its effectiveness. However, there is an immense potentiality to integrate DISSPRO, CBSP and other seed production initiative for long term sustainability.

- There is a strong need of developing a long term national seed strategy, vision and plan. Existing seed policy, acts and regulation is recommended to be amended for the effective enforcement and harmonization with international agreements and standards.

\section{REFERENCES}

Action Against Hunger, 2006. Annual Report. www.actionagainsthunger.org/

CDD, 2011a. Annual Progress Report 2067/068 BS (In Nepali). Crop Development Directorate, PP.55-59.

CDD, 2011b. Annual Report of Food Security Promotion Project 2067/068BS. Crop Development Directorate/ USAID, pp. 50.

CDD, 2010. Annual Progress Report 2066/067 BS (In Nepali). Crop Development Directorate.

SQCC, 2011. Seed Balance Sheet 2068/069. Seed Quality Control Centre, pp.171.

Seed Technology Division, 2011. Annual Report for SSNP-AF/SS 2 (Social Safety Net Project-Additional Funding/Seed Sub-component-2). Nepal Agriculture Research Council, pp.10. 